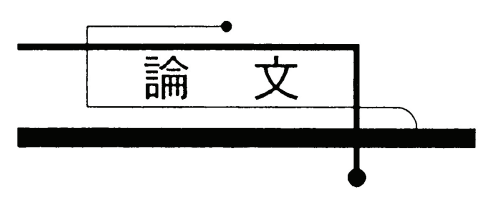

\title{
気液各相の初期非一様流速分布を有する気泡流中圧力波の弱非線形理論 * Weakly Nonlinear Theory on Pressure Waves in Bubbly Flows with Nonuniform Distributions of Flow Velocities in Gas and Liquid Phases
}

$$
\text { 前 田 泰 希 }{ }^{* *}
$$
MAEDA Taiki

\author{
金川哲 也 ${ }^{* * *}$ \\ KANAGAWA Tetsuya
}

\begin{abstract}
Weakly nonlinear propagation of plane pressure waves in a flowing water uniformly containing many spherical microbubbles is theoretically investigated. At the initial state, the gas and liquid phases have different flow velocity distributions as a small nonuniform effect in bubbly flows. The basic equations based on a two-fluid model are utilized to describe velocity distributions of gas and liquid phases. By using the method of multiple scales and the determination of size of three nondimensional ratios, we can systematically derive two types of nonlinear wave equations describing long-range propagation of waves. i.e., the Korteweg-de Vries-Burgers (KdVB) equation and the nonlinear Schrödinger (NLS) equation with variable coefficients. As a result, initial velocity distributions affect an advection effect of waves induced by a relative velocity between gas and liquid phases and a moving bubble.
\end{abstract}

Keywords: Bubbly flow, Weakly nonlinear wave, Nonuniform flow velocity distribution, KdV-Burgers equation, Nonlinear Schrödinger equation, Advection

\section{1. 緒 言}

ポンプを代表とする水を扱う水力機器において、 キャビテーションを伴う高速水流が生ずる。水流中 での圧力変動は、有限振幅の圧力波形成を導くが、気 泡振動がカギとなり、有限振幅 (非線形) 圧力波の伝 播は、水単相と大きく異なる様相を示すことが古く から指摘されてきた $[1,2]$ 。身の回りの水力機器の性 能向上の重要性を鑑みるに、気泡を含む水流中にお ける非線形圧力波の伝播への基礎的理解は、今もな お極めて重要な課題である。

理論研究の動向として、気泡を含む静止水中を伝 播する圧力波を記述する Korteweg-de Vries (KdV) 方程式の導出 [1] を皮切りに、多数の非線形波動方 程式が導かれてきた [1-9]。最近、著者らは、Fig. 1 に示すように、気泡流の線形分散関係を、周波数の 高低を基準に 2 分割し、低周波数の長波を記述する

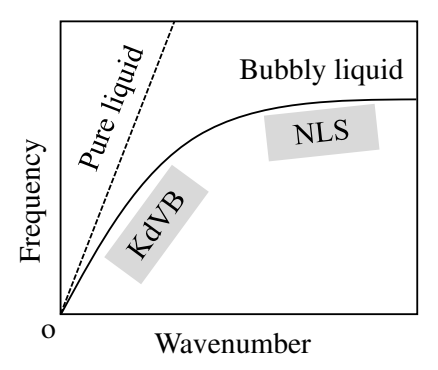

Fig. 1 Conceptual diagram of linear dispersion relation for pressure waves.

KdV-Burgers (KdVB) 方程式と、高周波数の短波を 記述する非線形 Schrödinger (NLS) 方程式を統一的 に導出した [10]。しかしながら、以上の先行研究を 含めた理論研究の殆どは、媒質が初期に静止状態に あるという仮定のもとでなされている。それゆえ、

* 2019.10.13 受付

** 筑波大学大学院システム情報工学研究科構造エネルギー工学専攻 $7305-8573$ 茨城県つくば市天王台 1-1-1 TEL: (029)853-5254ＦAX: (029)853-5207Ｅ-mail: kanagawa.tetsuya.fu@u.tsukuba.ac.jp

*** 筑波大学システム情報系構造エネルギー工学域 
気泡流すなわち媒質の初期の流れが圧力波伝播にい かなる影響を与えるのかという基礎的な知見すら、 あやふやなままという状況下にある。

そこで、本研究では、気相と液相でそれぞれ異な る流速の初期非一様分布を考慮した理論解析を行う。 気液各相の流速を記述可能な二流体モデル基礎方程 式系 [11] を用い、気液各相の流速の摂動展開に基づ き、初期静止媒質を仮定した著者らの先行研究 [10] で導かれた定数係数の KdVB と NLS の両方程式が、 初期非一様流速分布を変数係数の形で取り込んだ KdVB と NLS の両方程式に拡張される。その結果、 気液相間の相対速度や気泡自身の速度などが、圧力 波伝播に重要な影響を及ぼすことが判明した。

\section{2. 問題の定式化}

\section{1 問題設定}

多数の球形微細気泡を一様に含む水中を伝播する 平面進行圧力波を調べる。初期に気相と液相はそれ ぞれ独立な流速で流れている(初期非一様流速分布と よぶ)。圧力波の振幅は有限ではあるが、十分に小さ いものとする (弱非線形伝播)。気泡は球対称振動し ており、合体、分裂、生成、消滅は考慮しない。水の 圧縮性は考慮する。気相の粘性は無視するが、液相 の粘性は気液界面でのみ考慮する。気泡間の直接的 な相互作用、気液界面を通しての相変化、気相と液 相の熱伝導性、Reynolds 応力、重力は無視する。

\section{2 基礎方程式系}

気泡流の気液各相の流速を記述可能な基礎方程式 系として、二流体モデルにおける体積平均化された気 相と液相の質量保存式と運動量保存式を用いる [11]:

$$
\begin{aligned}
& \frac{\partial}{\partial t^{*}}\left(\alpha \rho_{\mathrm{G}}^{*}\right)+\frac{\partial}{\partial x^{*}}\left(\alpha \rho_{\mathrm{G}}^{*} u_{\mathrm{G}}^{*}\right)=0 \\
& \frac{\partial}{\partial t^{*}}\left[(1-\alpha) \rho_{\mathrm{L}}^{*}\right]+\frac{\partial}{\partial x^{*}}\left[(1-\alpha) \rho_{\mathrm{L}}^{*} u_{\mathrm{L}}^{*}\right]=0 \\
& \frac{\partial}{\partial t^{*}}\left(\alpha \rho_{\mathrm{G}}^{*} u_{\mathrm{G}}^{*}\right)+\frac{\partial}{\partial x^{*}}\left(\alpha \rho_{\mathrm{G}}^{*} u_{\mathrm{G}}^{* 2}\right)+\alpha \frac{\partial p_{\mathrm{G}}^{*}}{\partial x^{*}}=F^{*} \\
& \frac{\partial}{\partial t^{*}}\left[(1-\alpha) \rho_{\mathrm{L}}^{*} u_{\mathrm{L}}^{*}\right]+\frac{\partial}{\partial x^{*}}\left[(1-\alpha) \rho_{\mathrm{L}}^{*} u_{\mathrm{L}}^{* 2}\right] \\
& +(1-\alpha) \frac{\partial p_{\mathrm{L}}^{*}}{\partial x^{*}}+P^{*} \frac{\partial \alpha}{\partial x^{*}}=-F^{*}
\end{aligned}
$$

ここで、上付き添え字 * は有次元の物理量であるこ とを表す。気相・液相間での運動量輸送項 $F^{*}$ として は、以下の付加質量力を用いる [12-14]:

$$
\begin{aligned}
& F^{*}=-\beta_{1} \alpha \rho_{\mathrm{L}}^{*}\left(\frac{\mathrm{D}_{\mathrm{G}} u_{\mathrm{G}}^{*}}{\mathrm{D} t^{*}}-\frac{\mathrm{D}_{\mathrm{L}} u_{\mathrm{L}}^{*}}{\mathrm{D} t^{*}}\right) \\
& -\beta_{2} \rho_{\mathrm{L}}^{*}\left(u_{\mathrm{G}}^{*}-u_{\mathrm{L}}^{*}\right) \frac{\mathrm{D}_{\mathrm{G}} \alpha}{\mathrm{D} t^{*}}-\beta_{3} \alpha\left(u_{\mathrm{G}}^{*}-u_{\mathrm{L}}^{*}\right) \frac{\mathrm{D}_{\mathrm{G}} \rho_{\mathrm{L}}^{*}}{\mathrm{D} t^{*}}
\end{aligned}
$$

ここで、係数 $\beta_{1} 、 \beta_{2} 、 \beta_{3}$ は球形気泡の場合では $1 / 2$ となるが、本解析では各項の寄与を明らかにするた めに、具体的な数值を代入することなく進める。微 分演算子 $\mathrm{D}_{\mathrm{G}} / \mathrm{D} t^{*}$ と $\mathrm{D}_{\mathrm{L}} / \mathrm{D} t^{*}$ は次式で定義される:

$$
\frac{\mathrm{D}_{\mathrm{G}}}{\mathrm{D} t^{*}} \equiv \frac{\partial}{\partial t^{*}}+u_{\mathrm{G}}^{*} \frac{\partial}{\partial x^{*}}, \quad \frac{\mathrm{D}_{\mathrm{L}}}{\mathrm{D} t^{*}} \equiv \frac{\partial}{\partial t^{*}}+u_{\mathrm{L}}^{*} \frac{\partial}{\partial x^{*}}
$$

Keller 式を気泡力学の方程式に用いる [15]:

$$
\begin{aligned}
& \left(1-\frac{1}{c_{\mathrm{L} 0}^{*}} \frac{\mathrm{D}_{\mathrm{G}} R^{*}}{\mathrm{D} t^{*}}\right) R^{*} \frac{\mathrm{D}_{\mathrm{G}}^{2} R^{*}}{\mathrm{D} t^{* 2}} \\
& +\frac{3}{2}\left(1-\frac{1}{3 c_{\mathrm{L} 0}^{*}} \frac{\mathrm{D}_{\mathrm{G}} R^{*}}{\mathrm{D} t^{*}}\right)\left(\frac{\mathrm{D}_{\mathrm{G}} R^{*}}{\mathrm{D} t^{*}}\right)^{2} \\
= & \left(1+\frac{1}{c_{\mathrm{L} 0}^{*}} \frac{\mathrm{D}_{\mathrm{G}} R^{*}}{\mathrm{D} t^{*}}\right) \frac{P^{*}}{\rho_{\mathrm{L} 0}^{*}}+\frac{R^{*}}{\rho_{\mathrm{L} 0}^{*} c_{\mathrm{L} 0}^{*}} \frac{\mathrm{D}_{\mathrm{G}}}{\mathrm{D} t^{*}}\left(p_{\mathrm{L}}^{*}+P^{*}\right)
\end{aligned}
$$

式 (7) の左辺は慣性項、右辺第 2 項は圧縮性液体中に おける音響放射減衰を記述する。

式 (1)-(4) と (7) を数学的に閉じるために、気相の ポリトロープ変化の状態方程式、液相の Tait 状態方 程式、気泡内気体の質量保存式、気液界面における 応力のつりあい式を用いる:

$$
\begin{aligned}
& \frac{p_{\mathrm{G}}^{*}}{p_{\mathrm{G} 0}^{*}}=\left(\frac{\rho_{\mathrm{G}}^{*}}{\rho_{\mathrm{G} 0}^{*}}\right)^{\gamma} \\
& p_{\mathrm{L}}^{*}=p_{\mathrm{L} 0}^{*}+\frac{\rho_{\mathrm{L} 0}^{*} c_{\mathrm{L} 0}^{*}}{n}\left[\left(\frac{\rho_{\mathrm{L}}^{*}}{\rho_{\mathrm{L} 0}^{*}}\right)^{n}-1\right] \\
& \frac{\rho_{\mathrm{G}}^{*}}{\rho_{\mathrm{G} 0}^{*}}=\left(\frac{R_{0}^{*}}{R^{*}}\right)^{3} \\
& p_{\mathrm{G}}^{*}-\left(p_{\mathrm{L}}^{*}+P^{*}\right)=\frac{2 \sigma^{*}}{R^{*}}+\frac{4 \mu^{*}}{R^{*}} \frac{\mathrm{D}_{\mathrm{G}} R^{*}}{\mathrm{D} t^{*}}
\end{aligned}
$$

\section{3 パラメータスケーリング}

著者らの先行研究 [10] で提案されたパラメータス ケーリング法を用いる。波の代表的な伝播速度 $U^{*}$ 、 波の代表的な波長 $L^{*}$ 、入射波の角周波数 $\omega^{*}$ に対し て、無次元数の大きさを以下のように定める [10]:

$$
\begin{aligned}
\frac{U^{*}}{c_{\mathrm{L} 0}^{*}} & \equiv \begin{cases}O(\sqrt{\epsilon}) \equiv V \sqrt{\epsilon}, & (\mathrm{KdVB}) \\
O\left(\epsilon^{2}\right) \equiv V \epsilon^{2}, & (\mathrm{NLS})\end{cases} \\
\frac{R_{0}^{*}}{L^{*}} & \equiv \begin{cases}O(\sqrt{\epsilon}) \equiv \Delta \sqrt{\epsilon}, & (\mathrm{KdVB}) \\
O(1) \equiv \Delta, & (\mathrm{NLS})\end{cases} \\
\frac{\omega^{*}}{\omega_{\mathrm{B}}^{*}} & \equiv \begin{cases}O(\sqrt{\epsilon}) \equiv \Omega \sqrt{\epsilon}, & (\mathrm{KdVB}) \\
O(1) \equiv \Omega, & (\mathrm{NLS})\end{cases}
\end{aligned}
$$

ここで、V、A、 $\Omega$ はいずれも $O(1)$ の定数である。ま た、 $\epsilon$ は波の無次元振幅であり、有限だが 1 に比べて 十分に小さい $(0<\epsilon \ll 1)$ 。単一気泡の固有角周波数 
$\omega_{\mathrm{B}}^{*}$ は次式で与えられる:

$$
\omega_{\mathrm{B}}^{*} \equiv \sqrt{\frac{3 \gamma\left(p_{\mathrm{L} 0}^{*}+2 \sigma^{*} / R_{0}^{*}\right)-2 \sigma^{*} / R_{0}^{*}}{\rho_{\mathrm{L} 0}^{*} R_{0}^{* 2}}}
$$

\section{4 多重尺度解析 [10]}

特異摂動法の一種である多重尺度法を用いる。ま ずは、独立変数として、時間 $t^{*}$ と空間座標 $x^{*}$ を、 $t=t^{*} / T^{*} 、 x=x^{*} / L^{*}$ と無次元化する。ここで、無次 元振幅 $\epsilon(\ll 1)$ を用いて、無次元独立変数 $t$ と $x$ に対 する、近傍場、遠方場 I、遠方場 II を表す新たな独立 変数を導入する $[16,17]$ :

$$
\begin{aligned}
& t_{0}=\epsilon^{0} t, \quad x_{0}=\epsilon^{0} x, \quad \text { (近傍場) } \\
& t_{1}=\epsilon^{1} t, \quad x_{1}=\epsilon^{1} x, \quad \text { (遠方場 I) } \\
& t_{2}=\epsilon^{2} t, \quad x_{2}=\epsilon^{2} x, \quad(\text { 遠方場 II) }
\end{aligned}
$$

ここから、偏微分演算子が展開される (微分展開法):

$$
\frac{\partial}{\partial t}=\sum_{i=0}^{j} \epsilon^{i} \frac{\partial}{\partial t_{i}}, \quad \frac{\partial}{\partial x}=\sum_{i=0}^{j} \epsilon^{i} \frac{\partial}{\partial x_{i}}
$$

ここで、KdVB 方程式の場合は $j=1$ であり、NLS 方程式の場合は $j=2$ である。

従属変数は、新たな独立変数 (16)-(18) の関数とみ なされ、 $\epsilon$ のべき級数に展開される:

$$
\begin{aligned}
& \frac{\alpha}{\alpha_{0}}=1+\epsilon \alpha_{1}+\epsilon^{2} \alpha_{2}+\cdots \\
& \frac{R^{*}}{R_{0}^{*}}=1+\epsilon R_{1}+\epsilon^{2} R_{2}+\cdots \\
& \frac{\rho_{\mathrm{L}}^{*}}{\rho_{\mathrm{L} 0}^{*}}= \begin{cases}1+\epsilon^{2} \rho_{\mathrm{L} 1}+\epsilon^{3} \rho_{\mathrm{L} 2}+\cdots, & (\mathrm{KdVB}) \\
1+\epsilon^{5} \rho_{\mathrm{L} 1}+\epsilon^{6} \rho_{\mathrm{L} 2}+\cdots, & (\mathrm{NLS})\end{cases} \\
& \frac{p_{\mathrm{L}}^{*}}{\rho_{\mathrm{L} 0}^{*} U^{* 2}}=p_{\mathrm{L} 0}+\epsilon p_{\mathrm{L} 1}+\epsilon^{2} p_{\mathrm{L} 2}+\cdots
\end{aligned}
$$

ここで、各 $\epsilon^{i}(0 \leq i)$ の係数はいずれも $O(1)$ であり、 式 (23) の液相圧力の係数 $p_{\mathrm{Li}}(0 \leq i)$ 、気相と液相の 初期密度比 $\rho_{\mathrm{G} 0}^{*} / \rho_{\mathrm{L} 0}^{*}$ 、表面張力 $\sigma$ 、液相粘性 $\mu$ 、初期圧 力 $p_{\mathrm{G} 0}$ と $p_{\mathrm{L} 0}$ の定義は先行研究 [10] と同一である。

\section{5 流速の摂動展開}

気相と液相の流速は、初期流速の存在と流速の非 一様性を考慮して、以下のように展開する [18]:

$$
\begin{aligned}
& \frac{u_{\mathrm{G}}^{*}}{U^{*}}= \begin{cases}\epsilon\left[u_{\mathrm{G} 01}\left(x_{1}\right)+u_{\mathrm{G} 1}\right]+\epsilon^{2} u_{\mathrm{G} 2}+\cdots, & (\mathrm{KdVB}) \\
\epsilon u_{\mathrm{G} 1}+\epsilon^{2}\left[u_{\mathrm{G} 02}\left(x_{2}\right)+u_{\mathrm{G} 2}\right]+\cdots, & (\mathrm{NLS})\end{cases} \\
& \frac{u_{\mathrm{L}}^{*}}{U^{*}}= \begin{cases}\epsilon\left[u_{\mathrm{L} 01}\left(x_{1}\right)+u_{\mathrm{L} 1}\right]+\epsilon^{2} u_{\mathrm{L} 2}+\cdots, & (\mathrm{KdVB}) \\
\epsilon u_{\mathrm{L} 1}+\epsilon^{2}\left[u_{\mathrm{L} 02}\left(x_{2}\right)+u_{\mathrm{L} 2}\right]+\cdots, & (\mathrm{NLS})\end{cases}
\end{aligned}
$$

これは、気泡数密度の初期非一様分布を考慮した先 行研究 [18] を、流速の初期非一様分布に拡張したも のに位置づけられる。ここで、 $u_{\mathrm{G} 01} 、 u_{\mathrm{L} 01} 、 u_{\mathrm{G} 02 、} u_{\mathrm{L} 02}$ は初期流速を表現する新たな項であり、 $u_{\mathrm{G} 01}$ と $u_{\mathrm{L} 01}$ は $\epsilon^{1}$ の項に導入し、 $u_{\mathrm{G} 02}$ と $u_{\mathrm{L} 02}$ は $\epsilon^{2}$ の項に導入し た。これら 4 項は、遠方場において現れる流速の初 期非一様分布を表現可能で、具体的には、 $u_{\mathrm{G} 01}$ と $u_{\mathrm{L} 01}$ は、KdVB 方程式の場合 (3 章) の遠方場の空間座標 $x_{1}$ のみに依存する既知関数とする。同様に、 $u_{\mathrm{G} 02}$ と $u_{\mathrm{L} 02}$ は、NLS 方程式の場合 (4 章) の最も遠い遠方場 II の $x_{2}$ のみに依存するとする。つまり、近傍場では、 初期流速は分布を持たない一様流速 (静止の場合をも 含む定数) と仮定しているが、弱い非線形性が長距離 の伝播を経て発現するほどに音源から遠い遠方場で は、初期流速の空間分布を表現可能となる。

\section{3. 低周波数の長波}

低周波数かつ長波長の領域 (Fig. 1 の KdVB) にお ける、非線形波の長距離伝播を記述する KdVB 方程 式を導く。

\section{1 近傍場 [10]}

本節で示す結果は先行研究 (文献 [10] の 3.1 節) と 同一であるため、要点のみを示す。

基礎方程式系 (1)-(4) と (7) に、パラメータスケー リング (12)-(14) と微分展開 (19)、摂動展開 (20)-(25) を代入すると、波の無次元振幅 $\epsilon$ に対する最低次の 線形方程式が導かれる:

$$
\begin{aligned}
& \frac{\partial \alpha_{1}}{\partial t_{0}}-3 \frac{\partial R_{1}}{\partial t_{0}}+\frac{\partial u_{\mathrm{G} 1}}{\partial x_{0}}=0 \\
& \alpha_{0} \frac{\partial \alpha_{1}}{\partial t_{0}}-\left(1-\alpha_{0}\right) \frac{\partial u_{\mathrm{L} 1}}{\partial x_{0}}=0 \\
& \beta_{1} \frac{\partial u_{\mathrm{G} 1}}{\partial t_{0}}-\beta_{1} \frac{\partial u_{\mathrm{L} 1}}{\partial t_{0}}-3 \gamma p_{\mathrm{G} 0} \frac{\partial R_{1}}{\partial x_{0}}=0 \\
& \left(1-\alpha_{0}+\beta_{1} \alpha_{0}\right) \frac{\partial u_{\mathrm{L} 1}}{\partial t_{0}}-\beta_{1} \alpha_{0} \frac{\partial u_{\mathrm{G} 1}}{\partial t_{0}} \\
& \quad+\left(1-\alpha_{0}\right) \frac{\partial p_{\mathrm{L} 1}}{\partial x_{0}}=0 \\
& R_{1}+\frac{\Omega^{2}}{\Delta^{2}} p_{\mathrm{L} 1}=0 \quad
\end{aligned}
$$

線形方程式系 (26)-(30) は、 $R_{1}$ のみを従属変数と する単一方程式にまとめられる:

$$
\begin{aligned}
& \frac{\partial^{2} R_{1}}{\partial t_{0}^{2}}-v_{\mathrm{p}}^{2} \frac{\partial^{2} R_{1}}{\partial x_{0}^{2}}=0 \\
& v_{\mathrm{p}} \equiv \sqrt{\frac{3 \alpha_{0}\left(1-\alpha_{0}+\beta_{1}\right) \gamma p_{\mathrm{G} 0}+\beta_{1}\left(1-\alpha_{0}\right) \Delta^{2} / \Omega^{2}}{3 \beta_{1} \alpha_{0}\left(1-\alpha_{0}\right)}}
\end{aligned}
$$


ここで、先行研究 [10] では、位相速度を $v_{\mathrm{p}} \equiv 1$ とお いていたが、本稿では一般性を保つために、 $v_{\mathrm{p}}$ のま ま進める。位相関数 $\varphi_{0}$ を

$$
\varphi_{0}\left(x_{0}, t_{0}\right) \equiv x_{0}-v_{\mathrm{p}} t_{0}
$$

と導入し、線形波動方程式 (31) の右向き進行波解 $R_{1}=f\left(\varphi_{0} ; t_{1}, x_{1}\right)$ に着目する。式 (26)-(30) より、 $\alpha_{1} 、 u_{\mathrm{G} 1} 、 u_{\mathrm{L} 1} 、 p_{\mathrm{L} 1}$ は $f$ の定数倍として表現される:

$$
\begin{aligned}
& \alpha_{1}=s_{1} f, \quad u_{\mathrm{G} 1}=s_{2} f, \\
& u_{\mathrm{L} 1}=s_{3} f,
\end{aligned}
$$

ここで、定数係数 $s_{i}(i=1,2,3,4)$ は先行研究 [10] の 式 (45) を参照されたい。

\section{2 遠方場}

近傍場と同一の手法を用いることにより、式 (1)(4)、(7) に対応する $\epsilon^{2}$ に対する方程式系を得る:

$$
\begin{aligned}
& \frac{\partial \alpha_{2}}{\partial t_{0}}-3 \frac{\partial R_{2}}{\partial t_{0}}+\frac{\partial u_{\mathrm{G} 2}}{\partial x_{0}}=K_{1}^{\prime} \\
& \alpha_{0} \frac{\partial \alpha_{2}}{\partial t_{0}}-\left(1-\alpha_{0}\right) \frac{\partial u_{\mathrm{L} 2}}{\partial x_{0}}=K_{2}^{\prime} \\
& \beta_{1} \frac{\partial u_{\mathrm{G} 2}}{\partial t_{0}} \beta_{1}-\frac{\partial u_{\mathrm{L} 2}}{\partial t_{0}}-3 \gamma p_{\mathrm{G} 0} \frac{\partial R_{2}}{\partial x_{0}}=K_{3}^{\prime} \\
& \left(1-\alpha_{0}+\beta_{1} \alpha_{0}\right) \frac{\partial u_{\mathrm{L} 2}}{\partial t_{0}}-\beta_{1} \alpha_{0} \frac{\partial u_{\mathrm{G} 2}}{\partial t_{0}} \\
& \quad+\left(1-\alpha_{0}\right) \frac{\partial p_{\mathrm{L} 2}}{\partial x_{0}}=K_{4}^{\prime} \\
& R_{2}+\frac{\Omega^{2}}{\Delta^{2}} p_{\mathrm{L} 2}=K_{5}^{\prime}
\end{aligned}
$$

ここで、式 (35)-(39) の非同次項は以下の通りである:

$$
\begin{gathered}
K_{1}^{\prime}=K_{1}-\frac{\mathrm{d} u_{\mathrm{G} 01}}{\mathrm{~d} x_{1}}+3 u_{\mathrm{G} 01} \frac{\partial R_{1}}{\partial x_{0}}-u_{\mathrm{G} 01} \frac{\partial \alpha_{1}}{\partial x_{0}} \\
K_{2}^{\prime}=K_{2}+\left(1-\alpha_{0}\right) \frac{\mathrm{d} u_{\mathrm{L} 01}}{\mathrm{~d} x_{1}}-\alpha_{0} u_{\mathrm{L} 01} \frac{\partial \alpha_{1}}{\partial x_{0}} \\
K_{3}^{\prime}=K_{3}-\beta_{1} u_{\mathrm{G} 01} \frac{\partial u_{\mathrm{G} 1}}{\partial x_{0}}+\beta_{1} u_{\mathrm{L} 01} \frac{\partial u_{\mathrm{L} 1}}{\partial x_{0}} \\
\quad-\beta_{2}\left(u_{\mathrm{G} 01}-u_{\mathrm{L} 01}\right) \frac{\partial \alpha_{1}}{\partial t_{0}} \\
K_{4}^{\prime}=K_{4}+\alpha_{0} u_{\mathrm{L} 01} \frac{\partial \alpha_{1}}{\partial t_{0}}-2\left(1-\alpha_{0}\right) u_{\mathrm{L} 01} \frac{\partial u_{\mathrm{L} 1}}{\partial x_{0}} \\
+\beta_{1} \alpha_{0} u_{\mathrm{G} 01} \frac{\partial u_{\mathrm{G} 1}}{\partial x_{0}}-\beta_{1} \alpha_{0} u_{\mathrm{L} 01} \frac{\partial u_{\mathrm{L} 1}}{\partial x_{0}} \\
+\beta_{2} \alpha_{0}\left(u_{\mathrm{G} 01}-u_{\mathrm{L} 01}\right) \frac{\partial \alpha_{1}}{\partial t_{0}} \\
K_{5}^{\prime}=K_{5}
\end{gathered}
$$

ここで、 $K_{i}(i=1,2,3,4,5)$ は初期静止の場合の先行 研究 [10] の付録 1 を参照されたい。初期流速の考慮
により、本研究では、非同次項に新たな項が現れた。 ここで、式 (40)(41) に現れる $x_{1}$ に関する導関数項 は、以下の式 (46) における $\varphi_{0}$ に関する偏微分演算 よりゼロとなるため、最終的な結果には寄与しない。

続いて、 $R_{2}$ に対する非同次方程式が導かれる:

$$
\begin{aligned}
& \frac{\partial^{2} R_{2}}{\partial t_{0}^{2}}-v_{\mathrm{p}}^{2} \frac{\partial^{2} R_{2}}{\partial x_{0}^{2}} \\
& =-\frac{1}{3} \frac{\partial K_{1}^{\prime}}{\partial t_{0}}+\frac{1}{3 \alpha_{0}} \frac{\partial K_{2}^{\prime}}{\partial t_{0}}+\frac{1-\alpha_{0}+\beta_{1}}{3\left(1-\alpha_{0}\right) \beta_{1}} \frac{\partial K_{3}^{\prime}}{\partial x_{0}} \\
& \quad+\frac{1}{3 \alpha_{0}\left(1-\alpha_{0}\right)} \frac{\partial K_{4}^{\prime}}{\partial x_{0}}-\frac{\Delta^{2}}{3 \alpha_{0} \Omega^{2}} \frac{\partial^{2} K_{5}^{\prime}}{\partial x_{0}^{2}}=K^{\prime}
\end{aligned}
$$

式 (45) に対する可解条件より $K^{\prime}=0$ が課される [10]。式 (33) を用いて偏導関数を書き換え、式 (40)(44) を代入すると、非同次項 $K^{\prime}$ が書き換えられる:

$$
\begin{gathered}
K^{\prime}=2 v_{\mathrm{p}} \frac{\partial}{\partial \varphi_{0}}\left[\frac{\partial f}{\partial t_{1}}+v_{\mathrm{p}} \frac{\partial f}{\partial x_{1}}+\Pi_{1} f \frac{\partial f}{\partial \varphi_{0}}+\Pi_{2} \frac{\partial^{2} f}{\partial \varphi_{0}^{2}}\right. \\
\left.+\Pi_{3} \frac{\partial^{3} f}{\partial \varphi_{0}^{3}}+\left(\Pi_{0}+\Pi_{4}\right) \frac{\partial f}{\partial \varphi_{0}}\right]=0
\end{gathered}
$$

\subsection{KdVB 方程式}

微分展開法 (19) を用いて、近傍場の式 (31) と遠方 場の式 (46) を組み合わせる:

$$
\begin{aligned}
\frac{\partial f}{\partial t}+v_{\mathrm{p}} & \frac{\partial f}{\partial x}+\epsilon\left[\Pi_{1} f \frac{\partial f}{\partial x}+\Pi_{2} \frac{\partial^{2} f}{\partial x^{2}}\right. \\
\left.+\Pi_{3} \frac{\partial^{3} f}{\partial x^{3}}+\left(\Pi_{0}+\Pi_{4}\right) \frac{\partial f}{\partial x}\right] & =0
\end{aligned}
$$

最後に、独立変数の変数変換を施すことにより、変 数係数の KdVB 方程式が導出される:

$$
\begin{aligned}
& \frac{\partial f}{\partial \tau}+\Pi_{1} f \frac{\partial f}{\partial \xi}+\Pi_{2} \frac{\partial^{2} f}{\partial \xi^{2}}+\Pi_{3} \frac{\partial^{3} f}{\partial \xi^{3}}+\Pi_{4} \frac{\partial f}{\partial \xi}=0 \\
& \tau \equiv \epsilon t, \quad \xi \equiv x-\left(v_{\mathrm{p}}+\epsilon \Pi_{0}\right) t
\end{aligned}
$$

ここで、各係数 $\Pi_{i}(i=0,2,3,4)$ は次式で与えられる:

$$
\begin{aligned}
& \Pi_{0}=-\frac{v_{\mathrm{p}}\left(1-\alpha_{0}\right) \Delta^{2} V^{2}}{6 \alpha_{0} \Omega^{2}} \\
& \Pi_{2}=-\frac{1}{6 \alpha_{0}}\left(4 \mu+\frac{\Delta^{3} V}{\Omega^{2}}\right) \\
& \Pi_{3}=\frac{v_{\mathrm{p}} \Delta^{2}}{6 \alpha_{0}} \\
& \Pi_{4}(\epsilon x)=u_{\mathrm{G} 01}-\frac{s_{1}}{6 \beta_{1}}\left(2 \beta_{1}-\beta_{2}\right)\left(u_{\mathrm{G} 01}-u_{\mathrm{L} 01}\right)
\end{aligned}
$$

また、 $\Pi_{1}$ は文献 [10] の付録 2 に示したきわめて複雑 な形となったため、本稿では割愛する。さらに、 $\Pi_{2}$ 


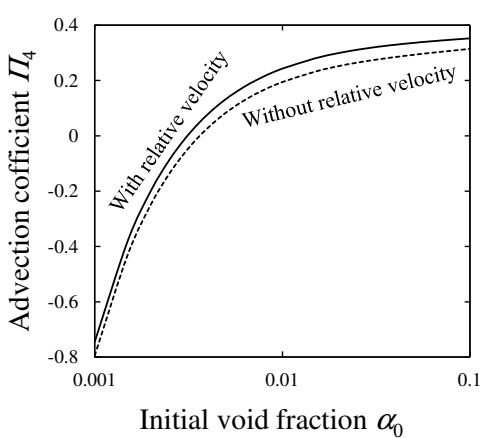

Fig. 2 The advection coefficient $\Pi_{4}$ against the initial void fraction $\alpha_{0}$ for $\Omega=1$, $\sqrt{\epsilon}=0.15, R_{0}^{*}=10 \mu \mathrm{m}, p_{\mathrm{L} 0}^{*}=$ $101325 \mathrm{~Pa}, \rho_{\mathrm{L} 0}^{*}=10^{3} \mathrm{~kg} / \mathrm{m}^{3}, \sigma^{*}=$ $0.0728 \mathrm{~N} / \mathrm{m}, c_{\mathrm{L} 0}^{*}=1.5 \times 10^{3} \mathrm{~m} / \mathrm{s}, \mu^{*}=$ $10^{-3} \mathrm{~Pa} \cdot \mathrm{s}, \gamma=1$ and $\beta_{1}=\beta_{2}=0.5$, $u_{\mathrm{G} 01}=0.4$ and $u_{\mathrm{L} 01}=0.3\left(u_{\mathrm{G} 01}\right.$ and $u_{\mathrm{L} 01}$ are constants).

は先行研究 $[10]$ と同一、 $\Pi_{0} 、 \Pi_{1} 、 \Pi_{3}$ は $v_{\mathrm{p}}$ の有無以 外は先行研究 [10] と同一となった。式 (47) の右辺第 2 項は非線形項、右辺第 3 項は散逸項、右辺第 4 項 は分散項、右辺第 5 項は (波の) 移流項である。した がって、遠方場においては非線形性、散逸性、分散性 が現れ、それらが競合する [10]。

新たに現れた移流項の係数 $\Pi_{4}$ について考察する。 初期非一様流速分布 $u_{\mathrm{G} 01}$ と $u_{\mathrm{L} 01}$ は任意関数であり、 これらを含む $\Pi_{4}$ は変数係数である。なお、移流係数 のうち、先行研究にも現れていた定数係数 $\Pi_{0}$ に注意 を要する。ここで、式 (53) の右辺第 1 項と右辺第 2 項は、気泡自体の流れ、および、気泡とその周囲液 体との速度差 (相対速度)をそれぞれ表す。後者のう ち、 $s_{1}\left(2 \beta_{1}-\beta_{2}\right) /\left(6 \beta_{1}\right)$ の大きさは概ね 0.5 であり、 式 (53) の右辺第 1 項 $u_{\mathrm{G} 01}$ の係数 1 の概ね半分であ る。したがって、初期流速を考慮する場合、相対速度 よりも気泡自体の流れの方が、波の移流に大きな影 響を及ぼすことがわかる。Fig. 2 に、初期流速がいず れも定数の場合について、移流係数 $\Pi_{4}$ の初期ボイド 率 $\alpha_{0}$ 依存性を示す。初期ボイド率 $\alpha_{0}$ が大きくなる につれて、移流係数 $\Pi_{4}$ が大きくなること、さらに、 気液の相対速度を考慮することで、相対速度を無視 する場合よりも移流係数が微増することもわかる。

\section{4. 高周波数の短波}

高周波数かつ短波長の領域 (Fig. 1 の NLS) におけ る、非線形波の長距離伝播を記述する NLS 方程式を 導く。近傍場 (4.1 節) と遠方場 I (4.2 節) の結果は先
行研究 (文献 [10] の 4.1 節と 4.2 節) と同様であるた め、要点のみを示す。

\section{1 近傍場 [10]}

式 (1)-(4) と（7)に、式 (12)-(14)、(19)、(20)-(25) を代入すると、 $\epsilon$ に対する最低次の線形方程式系が導 かれる。ここで、気相と液相の質量保存式と運動量 保存式は、低周波長波の場合の線形方程式 (26)-(29) と同一となった。一方、Keller 式は

$$
\frac{\partial^{2} R_{1}}{\partial t_{0}^{2}}+R_{1}+\frac{p_{\mathrm{L} 1}}{\Delta^{2}}=0
$$

となった。線形方程式系を $R_{1}$ に関する単一線形方程 式にまとめる:

$$
\begin{array}{r}
\frac{\partial^{2} R_{1}}{\partial t_{0}^{2}}-\left[\frac{\Delta^{2}}{3 \alpha_{0}}+\frac{1-\alpha_{0}+\beta_{1}}{\beta_{1}\left(1-\alpha_{0}\right)} \gamma p_{\mathrm{G} 0}\right] \frac{\partial^{2} R_{1}}{\partial x_{0}^{2}} \\
-\frac{\Delta^{2}}{3 \alpha_{0}} \frac{\partial^{4} R_{1}}{\partial t_{0}^{2} \partial x_{0}^{2}}=0
\end{array}
$$

式 (55) の左辺第3 項は分散項であり、低周波長波の場 合には現れなかった分散性が、近傍場で現れた [10]。 式 (55) の解に準単色波を仮定する [10,17, 19]:

$$
\begin{aligned}
& R_{1}=A\left(t_{1}, t_{2}, x_{1}, x_{2}\right) \mathrm{e}^{\mathrm{i} \theta}+\text { c.c. } \\
& \theta=k x_{0}-\Omega(k) t_{0}
\end{aligned}
$$

ここで、A は複素振幅、 $k\left(\equiv k^{*} L^{*}=k^{*} U^{*} / \omega_{\mathrm{B}}^{*}\right)$ は無 次元波数、 $\theta$ は位相関数、c.c. は複素共役を表す。式 (56)において、 $\mathrm{e}^{\mathrm{i} \theta}$ により搬送波が記述され、Aによ り包絡波が記述される $[17,19]$ 。解 (56) を線形方程 式系に代入すると、 $\alpha_{1} 、 u_{\mathrm{G} 1} 、 u_{\mathrm{L} 1} 、 p_{\mathrm{L} 1}$ はいずれも $R_{1}$ の定数倍として表現される:

$$
\begin{array}{ll}
\alpha_{1}=b_{1} R_{1}, & u_{\mathrm{G} 1}=b_{2} R_{1}, \\
u_{\mathrm{L} 1}=b_{3} R_{1}, & p_{\mathrm{L} 1}=b_{4} R_{1}
\end{array}
$$

ここで、定数係数 $b_{i}(i=1,2,3,4)$ は先行研究 [10] の 式 (69) を参照されたい。

\section{2 遠方場 I [10]}

$\epsilon^{2}$ の近似から、 $R_{2}$ に関する非同次方程式を得る:

$$
\begin{aligned}
\frac{\partial^{2} R_{2}}{\partial t_{0}^{2}}- & {\left[\frac{\Delta^{2}}{3 \alpha_{0}}+\frac{1-\alpha_{0}+\beta_{1}}{\beta_{1}\left(1-\alpha_{0}\right)} \gamma p_{\mathrm{G} 0}\right] \frac{\partial^{2} R_{2}}{\partial x_{0}^{2}} } \\
- & \frac{\Delta^{2}}{3 \alpha_{0}} \frac{\partial^{4} R_{2}}{\partial t_{0}^{2} \partial x_{0}^{2}}=\Gamma A^{2} \mathrm{e}^{2 \mathrm{i} \theta} \\
& +\mathrm{i}\left(-\frac{\partial D}{\partial \Omega}\right)\left(\frac{\partial A}{\partial t_{1}}+v_{\mathrm{g}} \frac{\partial A}{\partial x_{1}}\right) \mathrm{e}^{\mathrm{i} \theta}+\text { c.c. }
\end{aligned}
$$

ここで、 $D(k, \Omega)$ は以下のように定義される線形分散 関係である。

$$
D \equiv \frac{\Delta^{2} k^{2}\left(1-\Omega^{2}\right)}{3 \alpha_{0}}+\frac{\left(1-\alpha_{0}+\beta_{1}\right) \gamma p_{\mathrm{G} 0} k^{2}}{\beta_{1}\left(1-\alpha_{0}\right)}-\Omega^{2}
$$


可解条件より、式 (59) の右向き進行波の $\mathrm{e}^{\mathrm{i} \theta}$ の係数 はゼロとなり、包絡波 $A$ に関する線形波動方程式

$$
\frac{\partial A}{\partial t_{1}}+v_{\mathrm{g}} \frac{\partial A}{\partial x_{1}}=0
$$

が得られ、その解は次式で与えられる [10]:

$$
R_{2}=c_{0} A^{2} \mathrm{e}^{2 \mathrm{i} \theta}+\text { c.c. }
$$

式 (62) を $\epsilon^{2}$ に対する方程式系に代入すると、2 次の 摂動解が得られる:

$$
\left(\begin{array}{c}
\alpha_{2} \\
u_{\mathrm{G} 2} \\
u_{\mathrm{L} 2} \\
p_{\mathrm{L} 2}
\end{array}\right)=\left(\begin{array}{lll}
c_{1} & d_{1} & 0 \\
c_{2} & d_{2} & 0 \\
c_{3} & d_{3} & 0 \\
c_{4} & d_{4} & c_{\mathrm{s}}
\end{array}\right)\left(\begin{array}{c}
A^{2} \mathrm{e}^{2 \mathrm{i} \theta}+\text { c.c. } \\
\mathrm{i}\left(\partial A / \partial t_{1}\right) \mathrm{e}^{\mathrm{i} \theta}+\text { c.c. } \\
|A|^{2}
\end{array}\right)
$$

以上において、定数係数 $\Gamma 、 c_{0} 、 c_{i} 、 d_{i}(i=1,2,3,4)$ 、 $c_{\mathrm{S}}$ は先行研究 [10] の 4.2 節を参照されたい。

\section{3 遠方場 II}

$\epsilon^{3}$ に対する近似から、以下の方程式系を得る:

$$
\begin{aligned}
& \frac{\partial \alpha_{3}}{\partial t_{0}}-3 \frac{\partial R_{3}}{\partial t_{0}}+\frac{\partial u_{\mathrm{G} 3}}{\partial x_{0}}=N_{1}^{\prime} \\
& \alpha_{0} \frac{\partial \alpha_{3}}{\partial t_{0}}-\left(1-\alpha_{0}\right) \frac{\partial u_{\mathrm{L} 3}}{\partial x_{0}}=N_{2}^{\prime} \\
& \beta_{1} \frac{\partial u_{\mathrm{G} 3}}{\partial t_{0}}-\beta_{1} \frac{\partial u_{\mathrm{L} 3}}{\partial t_{0}}-3 \gamma p_{\mathrm{G} 0} \frac{\partial R_{3}}{\partial x_{0}}=N_{3}^{\prime} \\
& \left(1-\alpha_{0}+\beta_{1} \alpha_{0}\right) \frac{\partial u_{\mathrm{L} 3}}{\partial t_{0}}-\beta_{1} \alpha_{0} \frac{\partial u_{\mathrm{G} 3}}{\partial t_{0}} \\
& +\left(1-\alpha_{0}\right) \frac{\partial p_{\mathrm{L} 3}}{\partial x_{0}}=N_{4}^{\prime} \\
& \frac{\partial^{2} R_{3}}{\partial t_{0}^{2}}+R_{3}+\frac{p_{\mathrm{L} 3}}{\Delta^{2}}=N_{5}^{\prime}
\end{aligned}
$$

ここで、式 (64)-(68) の非同次項は以下の通りである:

$$
\begin{aligned}
N_{1}^{\prime}=N_{1} & -\frac{\mathrm{d} u_{\mathrm{G} 02}}{\mathrm{~d} x_{1}}+3 u_{\mathrm{G} 02} \frac{\partial R_{1}}{\partial x_{0}}-u_{\mathrm{G} 02} \frac{\partial \alpha_{1}}{\partial x_{0}} \\
N_{2}^{\prime}=N_{2} & +\left(1-\alpha_{0}\right) \frac{\mathrm{d} u_{\mathrm{L} 02}}{\mathrm{~d} x_{1}}-\alpha_{0} u_{\mathrm{L} 02} \frac{\partial \alpha_{1}}{\partial x_{0}} \\
N_{3}^{\prime}=N_{3} & -\beta_{1} u_{\mathrm{G} 02} \frac{\partial u_{\mathrm{G} 1}}{\partial x_{0}}+\beta_{1} u_{\mathrm{L} 02} \frac{\partial u_{\mathrm{L} 1}}{\partial x_{0}} \\
& -\beta_{2}\left(u_{\mathrm{G} 02}-u_{\mathrm{L} 02}\right) \frac{\partial \alpha_{1}}{\partial t_{0}} \\
N_{4}^{\prime}=N_{4} & +\alpha_{0} u_{\mathrm{L} 02} \frac{\partial \alpha_{1}}{\partial t_{0}}-2\left(1-\alpha_{0}\right) u_{\mathrm{L} 02} \frac{\partial u_{\mathrm{L} 1}}{\partial x_{0}} \\
& +\beta_{1} \alpha_{0} u_{\mathrm{G} 02} \frac{\partial u_{\mathrm{G} 1}}{\partial x_{0}}-\beta_{1} \alpha_{0} u_{\mathrm{L} 02} \frac{\partial u_{\mathrm{L} 1}}{\partial x_{0}} \\
& +\beta_{2} \alpha_{0}\left(u_{\mathrm{G} 02}-u_{\mathrm{L} 02}\right) \frac{\partial \alpha_{1}}{\partial t_{0}} \\
N_{5}^{\prime}=N_{5} & -2 u_{\mathrm{G} 02} \frac{\partial^{2} R_{1}}{\partial t_{0} \partial x_{0}}
\end{aligned}
$$

ここで、 $N_{i}(i=1,2,3,4,5)$ は先行研究 [10] の付録 1 を参照されたい。本研究で、初期流速を考慮したこ とにより、非同次項に新たな項が現れた。ここで、式 (69)(70) に現れる $x_{1}$ に関する導関数項は、後述の式 (74) において、 $t_{0}$ や $x_{0}$ に関する偏微分演算より、ゼ 口となるため、最終的な結果には寄与しない。

方程式系 (64)-(68) を、 $R_{3}$ に対する単一非同次方 程式にまとめる:

$$
\begin{gathered}
\frac{\partial^{2} R_{3}}{\partial t_{0}^{2}}-\left[\frac{\Delta^{2}}{3 \alpha_{0}}+\frac{1-\alpha_{0}+\beta_{1}}{\left(1-\alpha_{0}\right) \beta_{1}} \gamma p_{\mathrm{G} 0}\right] \frac{\partial^{2} R_{3}}{\partial x_{0}^{2}} \\
-\frac{\Delta^{2}}{3 \alpha_{0}} \frac{\partial^{4} R_{3}}{\partial t_{0}^{2} \partial x_{0}^{2}} \\
=-\frac{1}{3} \frac{\partial N_{1}^{\prime}}{\partial t_{0}}+\frac{1}{3 \alpha_{0}} \frac{\partial N_{2}^{\prime}}{\partial t_{0}}+\frac{1-\alpha_{0}+\beta_{1}}{3\left(1-\alpha_{0}\right) \beta_{1}} \frac{\partial N_{3}^{\prime}}{\partial x_{0}} \\
+\frac{1}{3 \alpha_{0}\left(1-\alpha_{0}\right)} \frac{\partial N_{4}^{\prime}}{\partial x_{0}}-\frac{\Delta^{2}}{3 \alpha_{0}} \frac{\partial^{2} N_{5}^{\prime}}{\partial x_{0}^{2}}=N^{\prime}
\end{gathered}
$$

式 (56)、(58)、(62)(63) を代入すると、非同次項 $N^{\prime}$ が書き換えられる:

$$
N^{\prime}=\Lambda_{1} \mathrm{e}^{3 \mathrm{i} \theta}+\Lambda_{2} \mathrm{e}^{2 \mathrm{i} \theta}+\Lambda_{3} \mathrm{e}^{\mathrm{i} \theta}+\text { c.c. }
$$

ここで、式 (74) の可解条件より、 $\Lambda_{3}=0$ となる [10]:

$$
\begin{aligned}
\Lambda_{3}= & -\frac{\partial D}{\partial \Omega}\left[\mathrm{i}\left(\frac{\partial A}{\partial t_{2}}+v_{\mathrm{g}} \frac{\partial A}{\partial x_{2}}\right)\right. \\
& \left.+v_{1}|A|^{2} A+\mathrm{i} v_{2} A+v_{3} \frac{\partial^{2} A}{\partial x_{1}^{2}}+v_{4} A\right]=0
\end{aligned}
$$

ここで、 $\Lambda_{1}$ と $\Lambda_{2}$ は、NLS 方程式の導出に寄与しな いことから割愛する。

\subsection{NLS 方程式}

微分展開法 (19) を用いて、遠方場 I と II それぞれ における包絡波の方程式 (61) と (76) を結合する:

$$
\begin{aligned}
& \mathrm{i}\left(\frac{\partial A}{\partial t}+v_{\mathrm{g}} \frac{\partial A}{\partial x}\right) \\
& +\epsilon^{2}\left(v_{1}|A|^{2} A+\mathrm{i} v_{2} A+v_{4} A\right)+v_{3} \frac{\partial^{2} A}{\partial x^{2}}=0
\end{aligned}
$$

最後に、独立変数の変数変換を施すことにより、NLS 方程式が導出される:

$$
\begin{aligned}
& \mathrm{i} \frac{\partial A}{\partial \tau}+v_{1}|A|^{2} A+\mathrm{i} v_{2} A+v_{3} \frac{\partial^{2} A}{\partial \xi^{2}}+v_{4} A=0 \\
& \tau=\epsilon^{2} t, \quad \xi=\epsilon\left(x-v_{\mathrm{g}} t\right)
\end{aligned}
$$

ここで、 $v_{i}(i=2,3,4)$ は次式で与えられる:

$$
\begin{aligned}
& v_{2}=\frac{\left(4 \mu+\Delta^{3} V\right) k^{2}}{2\left(3 \alpha_{0}+\Delta^{2} k^{2}\right)} \\
& v_{3}=-\frac{9 \alpha_{0} k v_{\mathrm{p}} \Delta^{2}}{2\left(3 \alpha_{0}+\Delta^{2} k^{2}\right)^{2}}=\frac{1}{2} \frac{\mathrm{d} v_{\mathrm{g}}}{\mathrm{d} k}
\end{aligned}
$$




$$
\begin{aligned}
v_{4}\left(\epsilon^{2} x\right)= & \frac{2 k^{2} v_{\mathrm{p}}}{\partial D / \partial \Omega}\left[u_{\mathrm{G} 02}+\frac{\Delta^{2}}{9 \alpha_{0}} k^{2} u_{\mathrm{G} 02}\right. \\
& \left.-\frac{b_{1}}{6 \beta_{1}}\left(2 \beta_{1}-\beta_{2}\right)\left(u_{\mathrm{G} 02}-u_{\mathrm{L} 02}\right)\right]
\end{aligned}
$$

また、 $v_{1}$ は文献 [10] の付録 2 に示したきわめて複雑 な形をとり、 $v_{1} 、 v_{2} 、 v_{3}$ はいずれも先行研究 [10] と 同一となった。式 (78) の右辺第 2 項は非線形項、右 辺第 3 項は散逸項、右辺第 4 項は分散項、右辺第 5 項は移流項であり、高周波短波の場合も、遠方場に おいて、非線形性、散逸性、分散性が競合する [10]。

新たに現れた移流係数 $v_{4}$ について考察する。流速 の初期非一様性より、移流係数 $v_{4}$ は変数係数であり、 式 (82) の右辺第 1 項と右辺第 3 項は、気泡自体の流 れ、および、気泡とその周囲液体との速度差 (相対速 度)をそれぞれ表す。KdVB 方程式の移流係数 $\Pi_{4}$ と 同様に、各項の係数の大きさの比較より、流れを考 慮する場合、相対速度よりも気泡自体の流れの方が、 波の移流に大きな影響を及ぼす。ここまでは KdVB 方程式の場合と同様であるが、NLS 方程式での移流 係数 $v_{4}$ には、右辺第 2 項に、KdVB 方程式での移流 係数 $\Pi_{4}$ では現れなかった、気泡振動に伴う項が現れ た。これは、遠方場 II における Keller 式の非同次項 (73) の右辺第 2 項に起因し、気泡の 2 次の非線形振 動の効果のうち慣性力を意味する。Fig. 3 に、初期 流速がいずれも定数の場合について、移流係数 $v_{4}$ の 波数 $k$ 依存性を示す。波数が $k=0.2$ 付近で $v_{4}$ が最 小になるが、それ以降は波数が大きくなるにつれて、 $v_{4}$ が大きくなる。また、気液の相対速度を考慮する ことで、相対速度を無視する場合よりも、 $v_{4}$ が増加 する。KdVB 方程式での移流係数 $\Pi_{4}$ と比べて、NLS 方程式での移流係数 $v_{4}$ では、相対速度の考慮による 移流係数の増加が大きくなることもわかる。

\section{5. 結 言}

気相と液相が初期に異なる流速分布のもとで流れ ている気泡流を考え、低周波長波の領域を記述する $\mathrm{KdVB}$ 方程式 (48) と、高周波短波の領域を記述する NLS 方程式 (78) を導出した。その結果、気相速度が 波の移流に大きく影響を与えることがわかった。ま た、気相と液相の相対速度を考慮したことで、気相 と液相が同速度であると仮定する場合に比べ、移流 係数の大きさが大きくなることもわかった。さらに、 非一様な流速分布を持つことから、初期静止を仮定し ていた先行研究 [10] では定数係数だった移流係数が 変数係数に変化した。今後の展望として、具体的な 波形を得るために、変数係数の場合の KdVB 方程式 と NLS 方程式の数值解を求めることが挙げられる。

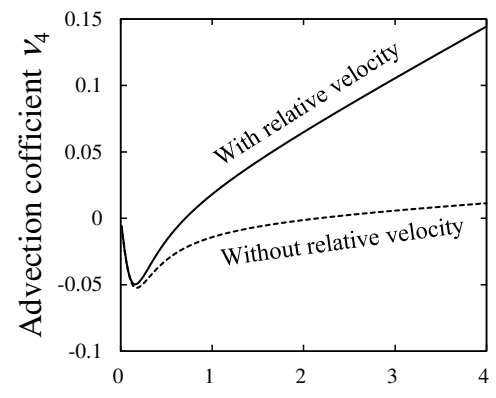

Wavenumber $k$

Fig. 3 The advection coefficient $v_{4}$ against the wavenumber $k$ for the case that the physical quantities except for $\epsilon$ and $\Omega$ are the same as those used in Fig. 2, where $\epsilon=0.07, u_{\mathrm{G} 01}=0.4$ and $u_{\mathrm{L} 01}=$ $0.3\left(u_{\mathrm{G} 01}\right.$ and $u_{\mathrm{L} 01}$ are constants); $\Omega$ varies with the variation of $k$.

\section{謝 辞}

本研究は、JSPS 科研費 (18K0394) およびカワイサ ウンド技術・音楽振興財団の助成を受けた。

\section{Nomenclature}

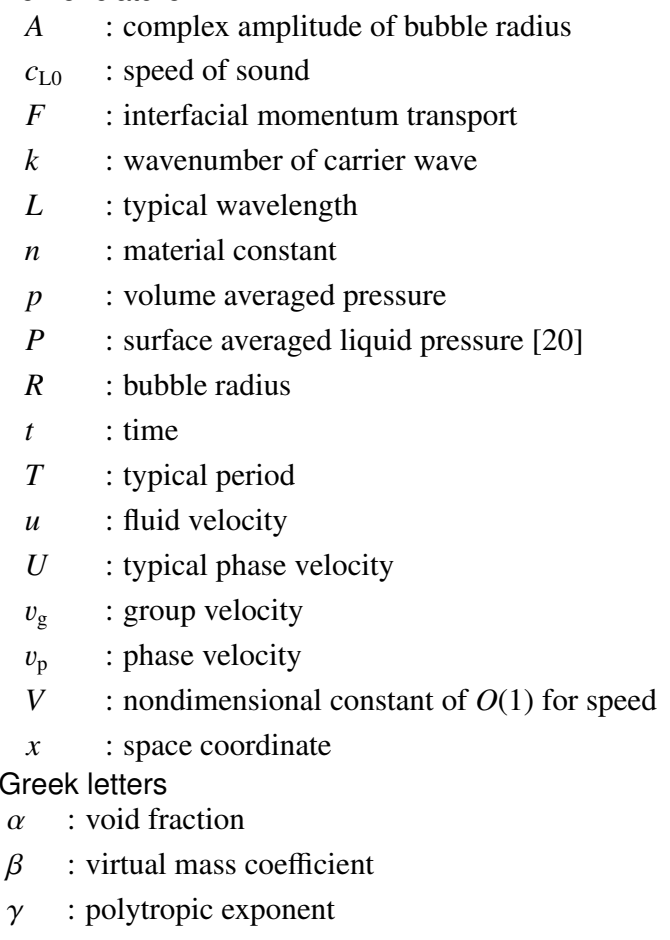


$\Delta \quad$ : nondimensional constant of $O(1)$ for length

$\epsilon \quad$ : nondimensional wave amplitude

$\theta \quad$ : phase function of wave

$\mu \quad$ : liquid viscosity

$v \quad:$ coefficient

$\xi \quad$ : space coordinate

$\Pi \quad$ : coefficient

$\rho \quad:$ density

$\sigma \quad$ : surface tension

$\tau \quad:$ time

$\varphi \quad:$ phase function

$\omega \quad$ : angular frequency of carrier wave

$\omega_{\mathrm{B}}$ : natural angular frequency of single bubble oscillations

$\Omega \quad$ : nondimensional constant of $O(1)$ for time Superscripts and Subscripts

$\mathrm{G}, \mathrm{L}$ : gas and liquid phases, respectively

$0 \quad$ : initial unperturbed state

* : dimensional quantity

\section{参考文献}

[1] van Wijngaarden, L., On the Equations of Motion for Mixtures of Liquid and Gas Bubbles, J. Fluid Mech., Vol. 33, 465-474 (1968).

[2] van Wijngaarden, L., One-Dimensional Flow of Liquids Containing Small Gas Bubbles, Ann. Rev. Fluid Mech., Vol. 4, 369-396 (1972).

[3] Noordzij, L. and van Wijngaarden, L., Relaxation Effects, Caused by Relative Motion, on Shock Waves in Gas-Bubble/Liquid Mixture, J. Fluid Mech., Vol. 66, 115-143 (1974).

[4] Kuznetsov, V. V., Nakoryakov, V. E., Pokusaev, B. G. and Shreiber, I. R., Propagation of Perturbations in a Gas-Liquid Mixture, J. Fluid Mech., Vol. 85, 85-96 (1978).

[5] Caflisch, R. E., Miksis, M. J., Papanicolaou, G. C. and Ting, L., Effective Equations for Wave Propagation in Bubbly Liquids, J. Fluid Mech., Vol. 153, 259-273 (1985).

[6] Nigmatulin, R. I., Dynamics of Multiphase Media, Hemisphere, New York (1991).

[7] Watanabe, M. and Prosperetti, A., Shock Waves in Dilute Bubbly Liquids, J. Fluid Mech., Vol. 274, 349-381 (1994).
[8] Khismatullin, D. B. and Akhatov, I. S., Sound-Ultrasound Interaction in Bubbly Fluids: Theory and Possible Applications, Phys. Fluids, Vol. 13 (12), 3582-3598 (2001).

[9] Smereka, P., A Vlasov Equation for Pressure Wave Propagation in Bubbly Fluids, J. Fluid Mech., Vol. 454, 287-325 (2002).

[10] Kanagawa, T., Yano, T., Watanabe, M. and Fujikawa, S., Unified Theory Based on Parameter Scaling for Derivation of Nonlinear Wave Equations in Bubbly Liquids, J. Fluid Sci. Technol., Vol. 5 (3), 351-369 (2010).

[11] Egashira, R., Yano, T. and Fujikawa, S., Linear Wave Propagation of Fast and Slow Modes in Mixtures of Liquid and Gas Bubbles, Fluid Dyn. Res., Vol. 34, 317-334 (2004).

[12] Yano, T., Egashira, R. and Fujikawa, S., Linear Analysis of Dispersive Waves in Bubbly Flows Based on Averaged Equations, J. Phys. Soc. Jpn., Vol. 75 (10), 104401 (2006).

[13] Eames, I. and Hunt, J. C. R., Forces on Bodies Moving Unsteadily in Rapidly Compressed Flows, J. Fluid Mech., Vol. 505, 349-364 (2004).

[14] Zhang, D. Z. and Prosperetti, A., Averaged Equations for Inviscid Disperse Two-Phase Flow, J. Fluid Mech., Vol. 267, 185-219 (1994).

[15] Keller, J. B. and Kolodner, I. I., Damping of Underwater Explosion Bubble Oscillations, J. Appl. Phys., Vol. 27 (10), 1152-1161 (1956).

[16] Nayfeh, A. H., Perturbation Methods, Wiley, New York (1973).

[17] Jeffrey, A. and Kawahara, T., Asymptotic Methods in Nonlinear Wave Theory, Pitman, London (1982).

[18] Kanagawa, T., Two Types of Nonlinear Wave Equations for Diffractive Beams in Bubbly Liquids with Nonuniform Bubble Number Density, J. Acoust. Soc. Am., Vol. 137 (5), 2642-2654 (2015).

[19] Whitham, G. B., Linear and Nonlinear Waves, Wiley, New York (1974).

[20] Jones, A. V. and Prosperetti, A., On the Suitability of First-order Differential Models for Two-phase Flow Prediction, Int. J. Multiph. Flow, Vol. 11 (2), 133-148 (1985). 